\title{
Anxiety Level vis-à-vis Breakfast Habits of The Students
}

Jeff S. Alferez ${ }^{1 \#}$ \& Jerald C. Moneva ${ }^{2}$

1.2 Jagobiao National High School, Jagobiao, Mandaue City, Cebu, Philippines.

\# corresponding author

Type of Work: Peer-Reviewed

DOl: http://dx.doi.org/10.21013/jems.v16.n1.p8

\section{How to cite this paper:}

Alferez, J.S., Moneva, J.C. (2020). Anxiety Level vis-à-vis Breakfast Habits of The Students. IRA International Journal of Education and Multidisciplinary Studies (ISSN 2455-2526), 16(1), 48-58. doi: http://dx.doi.org/10.21013/jems.v16.n1.p8

(C) Institute of Research Advances.

This work is licensed under a Creative Commons Attribution-Non Commercial 4.0 International License subject to a proper citation to the publication source of the work.

Disclaimer: The scholarly papers as reviewed and published by the Institute of Research Advances (IRA) are the views and opinions of their respective authors and are not the views or opinions of the IRA. The IRA disclaims of any harm or loss caused due to the published content to any party.

Institute of Research Advances is an institutional publisher member of Publishers International Linking Association Inc. (PILA-CrossRef), USA. The institute is an institutional signatory to the Budapest Open Access Initiative, Hungary advocating the open-access of scientific and scholarly knowledge. The Institute is a registered content provider under Open Access Initiative Protocol for Metadata Harvesting (OAI-PMH).

The journal is indexed \& included in WorldCat Discovery Service (USA), CrossRef Metadata Search (USA), WorldCat (USA), OCLC (USA), Open J-Gate (India), EZB (Germany) Scilit (Switzerland), Airiti (China), Bielefeld Academic Search Engine (BASE) of Bielefeld University, Germany, PKP Index of Simon Fraser University, Canada. 


\begin{abstract}
Breakfast as the most significant meal of the day is needed for the students to take before going to school. However, some students are skipping their breakfast and their body responses to this eating behavior remain unclear. This study examined students' anxiety levels in school as a response after taking and not taking breakfast before going to school. Students are examined and there are students who eat breakfast and students who do not eat breakfast before going to school. Then, each student is given a test that measures their school anxiety level in the morning. Using weighted mean, students who eat breakfast got an overall weighted mean of which is interpreted as a disagreement of being anxious in school. On the other hand, Students who did not eat their breakfast got an overall weighted mean of which is also interpreted to disagree with being anxious. Also, it was found out that both students who eat breakfast and who don't eat breakfast got midlevel of anxiety. Then, the ANOVA analysis resulted in a significance which is higher than the alpha. Therefore, there is no significant association between the anxiety level of the students who take breakfast and who do not take breakfast. In addition, students both taking breakfast or not taking breakfast do have a normal level of anxiety and breakfast can't give any effects to their anxiety level at all.
\end{abstract}

\title{
Introduction
}

Keywords: Anxiety, Anxiety Level, Breakfast, Students

Maintaining ones' health involves the eating habit of the person. The amount of work the person exerts in a day must be equivalent to the amount of energy to be consumed. There are 3 meals in a day namely breakfast, lunch, and dinner. Each meal has a specific time of consumption in which breakfast is taken in the morning, lunch in the afternoon, and dinner in the evening. A healthy diet also focused on the consumption of meals and more likely believing that the more frequent and smaller amount of meals taken, the better metabolic rate one will have.

Breakfast is important to children's overall dietary quality as it gives more energy and protein [1]. Furthermore, morning meals will break the fasting done on hours between dinner and breakfast. It needs a bigger amount of food consumption to start the day with enough energy throughout the morning before the next meal. So, skipping breakfast is like skipping all the benefits gotten in the morning meal and taking oneself to its possible negative side effects. Also, making breakfast skipping as a habit could hinder ones' productivity and creativity either in work or school especially in the morning.

The breakfast skipping has occurred to the students especially the morning sessions. Irregular breakfast consumption occurs because of either lack of time in preparing breakfast or loss of appetite. Also, the students nowadays eat breakfast fewer than 3 days in a typical school week [2]. It was considered of having abnormal breakfast consumption. This irregular breakfast eating habit will typically affect their performance. There is a positive association between the frequency of breakfast consumption and students' school grades and achievements, in other words, school performance [3]. Higher school performance includes participation. Students' participation appears whenever they have their interest in the discussion unless they feel unease, uncomfortable, scared, or all in all, anxious.

Since, being anxious or having the feeling of anxiety was occurring across people, the possible causes of anxiety were still in the process of inquiry. There are a lot of results in different researches about anxiety and one of these is about the exam anxiety of students that mostly causes by overexertion and study overnight instead of refreshing before exams that result to lower performance in school exams [4]. Also, exam anxiety negatively affects the academic success of the secondary level of students [5]. Based on the observations between anxiety and breakfast, the researcher wants to seek and know the level of anxiety of the students who take breakfast and who do not take breakfast before their first academic subject. 


\section{Statement of Purpose}

The study aims to assess the level of anxiety of the students who take breakfast and students who do not take breakfast. Also, to know what is the students' level of anxiety who are taking breakfast and who are not taking breakfast and if there a significant difference in anxiety level between the students who take breakfast and students who do not take breakfast.

\section{Hypothesis}

Ho - There is no significant difference in anxiety levels between students who take breakfast and students who do not take breakfast.

$\mathrm{Ha}$ - There is a significant difference in anxiety levels between students who take breakfast and students who do not take breakfast.

\section{Review of Related Literature}

In this chapter, it consists of related studies and literature from the past. The information is given of each related study, especially the results, findings and conclusion, where the significant information placed give the researcher further knowledge about the important information that can be used for the present study.

Adolescent consumers of a good-quality breakfast are significantly higher intakes of micronutrients from the food such as bread, water, fruit and fruit juices, milk, and vegetables resulting in a better overall dietary pattern [10]. To consider, some children and adolescents tend to skip breakfast and some is taking a readyto-eat (RTE) breakfast such as cereals resulting them to have lower intake of fat and cholesterol and higher intake of dietary fiber, carbohydrates, and micronutrients than the breakfast-skippers and other breakfast consumers and breakfast-skippers are also having bigger waist circumference and body mass index than the RTE consumer and other breakfast eaters [11].

Parents are statistically the most significant factor that is associated with adolescent's breakfast eating and breakfast skipping among adolescents is associated with compromising behaviors such as smoking, infrequent exercise, lower education level, and frequent alcohol [12]. Also, breakfast skipping was associated with high body mass index (BMI), larger waist circumference, and poorer cardiometabolic profile [13].

In terms of education in relation to breakfast, breakfast provided to children resulted in the improvements in children's attendance, achievements, and nutritional status [14]. Not just that, breakfast also enhance the students' nutrient intake which is associated with significant improvements in academic performance and psychosocial functioning and decreases the students' hunger [15]. Receiving breakfast also gives improvements to verbal fluency of the students particularly the children who are undernourished [16]. In relation to our health, frequent breakfast consumption gives an impact on children's health and well-being and improves cognitive function related to memory, test grades, and school attendance [17]. Missing breakfast causes increase energy or food intake which is associated with a higher feeling of hunger and desire to eat and lower feeling of fullness because breakfast affects metabolic and endocrine responses to the foods consumed later in the day [18].

Learning and cognition of the students interfere with the omission of breakfast especially to those learners who are least in terms of nutrition [19]. On the other hand, if breakfast is being consumed on a regular basis, it can improve the students' cognitive performance specifically on memory [20,21]. Breakfast consumption gives higher blood glucose concentration and increases energy and fullness and lessens the feeling of tiredness and hunger [22]. Also, the effects of breakfast on the cognitive performance of children are based on the compositional differences of food they consumed, particularly in special memory, shortterm memory, visual perception, and auditory vigilance [23].

There are improvements in mental health if breakfast that consist of more nutrients like cereals is regularly consumed like lowering the level of perceived stress, less depressed, and less emotional distress which can 
develop a much healthier lifestyle and lesser health-compromising behaviors like smoking and drinking too much alcohol [8].

Anxiety, a mental illness, is been occurring to anyone and some make eating a larger amount of food as a way of reducing anxiety, though it is not that healthy it is somehow effective [24]. A strong risk of recurrent anxiety disorder of young adults is granted by the anxiety disorder during adolescence and most anxiety disorders in young adults are preceded by anxiety disorder or depression in adolescence [25]. Anxiety does not impair the performance effectiveness when it leads to the use of compensatory strategies like enhancing effort but, it gives an adverse effect to the processing efficiency which depends on two central executive functions involving attentional control: Inhibition and shifting [26].

In relation to anxiety, there is also called as social anxiety that happens more like in doing a presentation or talk with large audiences and arises when people are motivated to make a preferred impression of the audiences but doubt that they will do so and perceive or imagine of getting negative evaluative reaction to the important audiences [27]. Also, we have what we called as exams' anxiety which is more common to the students that have a negative relation to self-esteem and optimism and it is linked with the students' perceptions in their educational environment and their personality characteristics [28].

Students do have midlevel of test anxiety and most girls are having higher test anxiety compared to the boys and what creates anxiety is the fear of being unsuccessful or not reaching expectations [5]. Test anxious individuals need to direct their attention on task-relevant variables to improve performance and avoid from self-evaluative rumination [29]. Test anxiety that causes poor performance is related directly to fear of negative evaluation, defensiveness, and other forms of anxiety and relates inversely with self-esteem [30].

In some cases, language learning also produces anxiety to the students that is called foreign language anxiety, in which the most threatening part of that is speaking the target language, resulting in the anxious students some difficulties for developing communicative competence [31]. Language anxiety also causes poor language learning and the possible sources of this anxiety include authentic self-presentation and various language teaching practices [32]. To create a better and lesser anxiety classroom-environment is just to create genuine motivation to students and making them be more interested in learning foreign languages and avoiding them to have unpleasant emotions that can create stress [33].

Students'math anxiety affects their performance on math-related tasks and transitory disruption of working memory that is caused by long-term avoidance of math that may result in lesser mastery and competence and needed to be given empirical attention [34]. It also resulted in poorer math performance because of lower competence and achievement [35]. Performance depresses whenever the person is having math anxiety and it seems to be learned condition in behavioral than cognitive in nature and it can be lessened by having higher achievements [36].

Furthermore, some children with one more anxious parent respond to child-focused cognitive-behavioral therapy (CBT), which teaches children coping skills for anxiety, less favorably than the children with nonanxious parents. Then, after the provision of parent's anxiety management (PAM), the efficacy of childfocused cognitive behavioral therapy enhanced for children with one or more anxious parents but not to the children with nonanxious parents. This simply means that the presence of anxiety towards either one or two parent's help for a successful outcome for the child-focused CBT of children [37].

\section{Methodology}

\section{Environment}

The researcher conducted the study in Jagobiao National High School - Senior High Department. Two different buildings and a total of 8 occupied rooms in different offered strands: Accountancy and Business Management (ABM), Humanities and Social Sciences (HUMSS), Science, Technology, Engineering, and 
Mathematics (STEM), General Academic Strand (GAS), and Technical Vocational and Livelihood Drafting (TVL-Drafting).

\section{Respondent}

Students in Jagobiao National High School - Senior High Department is the chosen respondent of the researcher. A total of 228 respondents include all grade 11 and 12 students. The researcher chose Senior High students as a respondent of study because Senior High students could answer the questionnaire appropriately and reliably. Also, the researcher added 40 grade 10 junior students, for some lacking respondents of those who do not eat breakfast which is actually needed for analysis. Furthermore, Senior High students and grade 10 junior students are the most suitable and reachable to be the respondent of the study.

\section{Design}

The researcher used a descriptive correlation research design. The researcher aims to understand the relations or differences between anxiety and the breakfast of students. Also, it is suitable for the quantitative type of research.

\section{Instrument}

The researcher used a measurement instrument database namely "Classroom Anxiety Measure" by Richmond (2013). This questionnaire measures the students' anxiety that is used for data analysis and interpretation. The questions provided are answerable by using numbers 1, 2, 3, 4, and 5 that stands for (1) strongly disagree, (2) disagree, (3) neutral, (4) agree, and (5) for strongly agree. The researcher may also add some follow up questions that focus on the student's information including breakfast: Either they eat breakfast or not.

\section{Data Gathering Procedure}

The researcher gathered data that starts every 6:30 am to 7:20 am as it measures the students' anxiety during their first academic subject and classifies students who take breakfast and who do not take breakfast. The researcher will give the respondents or students the questionnaires and let them answer all the questions for about 20 minutes or more as long as it doesn't excess in the specified time limitations and give their answers that are needed for analysis and interpretation. The researcher should at least finish 1 room in a day and the gathering of data could last about at most 3 weeks.

\section{Statistical treatment}

The researcher used a weighted mean for analyzing the collected data of the dependent variable which is the anxiety level. The individualized mean of each classified students, who eat breakfast and who do not eat breakfast, was calculated. Additionally, the researcher used the percentage and frequency of students who eat breakfast and who do not eat breakfast according to their level of anxiety. The researcher added the ANOVA for the interpretation and to determine if there is a significant association between anxiety levels of students who take breakfast and who do not take breakfast. 
Presentation, Analysis, and Interpretation of Data

Table 1 Anxiety Level of Students Who Eat Breakfast

\begin{tabular}{ccc}
\hline INDICATORS & Weighted Mean & Interpretation \\
\hline 1. I feel apprehensive. & 2.78 & Neutral \\
2. I feel disturbed. & 2.33 & Disagree \\
3. I am peaceful. & 1.56 & Strongly disagree \\
4. I feel relaxed. & 1.88 & Disagree \\
5. I feel uneasy. & 2.51 & Disagree \\
6. I feel self-assured. & 2.01 & Disagree \\
7. I feel fearful. & 2.56 & Disagree \\
8. I feel ruffled. & 2.48 & Disagree \\
9. I am jumpy. & 2.58 & Disagree \\
10. I feel composed. & 2.22 & Disagree \\
11. I am insecure. & 2.27 & Disagree \\
12. I feel satisfied. & 1.61 & Strongly Disagree \\
13. I feel safe. & 1.26 & Strongly Disagree \\
14. I feel flustered. & 2.71 & Neutral \\
15. I am cheerful. & 1.34 & Strongly Disagree \\
16. I feel happy. & 1.19 & Strongly Disagree \\
17. I feel dejected. & 2.48 & Disagree \\
18. I feel pleased. & 1.90 & Disagree \\
19. I feel good. & 1.31 & Strongly Disagree \\
20. I feel unhappy. & 2.10 & Disagree \\
& & \\
\hline TOTAL AVERAGE & 2.05 & Disagree \\
\hline
\end{tabular}

Legend: Strongly Agree (4.21-5.00), Agree (3.41-4.20), Neutral (2.61-3.40), Disagree (1.81, 2.60), Strongly Disagree (1.00-1.80)

Table one (1) shows the weighted means of each statement provided in the questionnaire to indicate the anxiety level of the students. As we can see, some statements are bolded and some are not. The bolded ones are statements that show low anxiety level while the other statements that are not bolded show a high anxiety level. So, to identify the anxiety level of a student base on their own understanding of each bolded statement, reverse scoring is applied and it seems likely that the scores given of each bolded statements indicate the level of agreement of the students to the opposing party of what the bolded statements actually meant. Base on table one, the first three statements who got the highest weighted mean are I feel apprehensive (2.78), I feel flustered (2.71), and I am jumpy (2.58). This shows that students who eat breakfast are having a stronger feeling that they may still have chances to feel apprehensive, flustered, and jumpy in school even taking breakfast. Then, in the very least is the statement I feel happy (1.19) which after the reverse scoring, the actual weighted mean of this statement is (3.81) that shows students who eat breakfast agreed of the statement that they feel happy. Overall, the total average of all weighted mean is 
(2.05) which means that the students who eat breakfast disagree with feeling anxious or having a high anxiety level.

Table 2 Who Eat Breakfast

\begin{tabular}{ccc}
\hline Indicators & Frequency & Percent \\
\hline No Anxiety at all & 2 & 1.2 \\
Less Anxiety Level & 71 & 43.8 \\
Fair Anxiety Level & 88 & 54.3 \\
Moderate Anxiety Level & 1 & .6 \\
High Anxiety Level & 0 & 0 \\
\hline Total & 162 & 100.0 \\
\hline
\end{tabular}

Table (2) indicates the frequency and percentage of students who eat breakfast according to their anxiety level. On the ratings, most students who eat breakfast are having a fair anxiety level (54.3\%) and some others are having less anxiety level (43.8\%). There are only a few students who we can consider having no anxiety at all $(1.2 \%)$ and only one student $(.6 \%)$ that was indicated as having a moderate anxiety level. Lastly, there are no students who are having a high rate of anxiety level. So all in all, students who eat breakfast are mostly having an average rate of anxiety level.

Also, breakfast could improve the cognitive functions of the students that are related to memory, their school attendance, and even test grades [17]. Especially, those student consumers of good-quality breakfast, which resulted in them to be a significantly higher intake of selected micronutrients and had a healthy diet [10]. Ready to eat cereal eaters which is also a good quality breakfast also gets better nutrient intake profiles [11].

Table 3 Anxiety Level of Students Who Do Not Eat Breakfast

\begin{tabular}{ccc}
\hline INDICATORS & Weighted Mean & Interpretation \\
\hline 1. I feel apprehensive. & 2.92 & Neutral \\
2. I feel disturbed. & 2.63 & Neutral \\
3. I am peaceful. & 2.02 & Disagree \\
4. I feel relaxed. & 2.08 & Disagree \\
5. I feel uneasy. & 2.65 & Neutral \\
6. I feel self-assured. & 2.25 & Disagree \\
7. I feel fearful. & 2.58 & Disagree \\
8. I feel ruffled. & 2.46 & Disagree \\
9. I am jumpy. & 2.38 & Disagree \\
10. I feel composed. & 2.19 & Disagree \\
11. I am insecure. & 2.36 & Disagree \\
12. I feel satisfied. & 1.84 & Disagree \\
13. I feel safe. & 1.59 & Strongly Disagree \\
14. I feel flustered. & 2.73 & Neutral \\
15. I am cheerful. & 1.63 & Strongly Disagree \\
16. I feel happy. & 1.46 & Agree \\
17. I feel dejected. & 2.69 & Neutral
\end{tabular}




\begin{tabular}{ccc}
\hline 18. I feel pleased. & 1.95 & Disagree \\
19. I feel good. & 1.45 & Strongly Disagree \\
20. I feel unhappy. & 2.37 & Disagree \\
\hline TOTAL AVERAGE & 2.21 & Disagree \\
\hline
\end{tabular}

Legend: Strongly Agree (4.21-5.00), Agree (3.41-4.20), Neutral (2.61-3.40), Disagree (1.81, 2.60), Strongly Disagree (1.00-1.80)

Table three (3) also has bolded and not bolded statements and different way of dealing with the scores provided of each two different statements. The different thing is that this table shows the anxiety level of the students who do not eat their breakfast. In these weighted means, there are 5 statements who got neutral interpretation compared to table one who only got 2 statements that reach the neutral level, and these are the I feel apprehensive (2.92), I feel flustered (2.73), I feel dejected (2.69), I feel uneasy (2.65), and I feel disturbed (2.63).

This shows that the students who do not eat breakfast are more likely of having the chance to feel anxious like the feeling of apprehensive, flustered, dejected, uneasy, and disturbed. Also, this table of a score of the students who do not eat breakfast shows that not taking breakfast are more likely to feel anxious than those who eat breakfast.

However, the overall total average of the weighted means of each statement (2.21) of this table still has a disagree interpretation, though it is higher than the first table. So, the students who do not eat breakfast still disagree with having the feeling of being anxious in school. However, skipping breakfast for a long period of time may give a detrimental effect on the cardiometabolic health of the person [13]. Also, breakfast skipping is significantly associated with health-compromising behaviors like smoking, frequent alcohol use, infrequent exercise, etc. [12]. In addition, omitting breakfast interferes learning and cognition of students especially those students who are least in nutrition [19].

Table 4 Who Do Not Eat Breakfast

\begin{tabular}{ccc}
\hline Indicators & Frequency & Percent \\
\hline No Anxiety at all & 1 & .9 \\
Less Anxiety Level & 37 & 34.9 \\
Fair Anxiety Level & 63 & 59.4 \\
Moderate Anxiety Level & 5 & 4.7 \\
High Anxiety Level & 0 & 0 \\
\hline Total & 106 & 100.0 \\
\hline
\end{tabular}

Table (4) also indicates the frequency and percentage of students according to their anxiety level, but these students are those who do not eat breakfast. There's a bit different base on the percentage of each indicator, but still, no one was indicated of having a high anxiety level. Base on its percentage which differs from the table two (2), students who are having a fair anxiety level (59\%) increase their percentage rate, and also the moderate anxiety level $(4.7 \%)$. While the students who are having no anxiety at all and less anxiety level $(.9 \%, 34.9 \%)$ decrease. Therefore, students who do not eat breakfast are most likely to have a higher rate of having anxiety levels more than the students who eat breakfast. 
Table 5 Students Who Take Breakfast and Who Do Not Take Breakfast

\begin{tabular}{|c|c|c|c|c|c|}
\hline & Sum of Squares & $\mathrm{df}$ & Mean Square & $\mathrm{F}$ & Sig. \\
\hline Between Groups & 3.745 & 18 & .208 & 7.866 & .274 \\
\hline Within Groups & .026 & 1 & .026 & & \\
\hline Total & 3.772 & 19 & & & \\
\hline
\end{tabular}

On table five (5), shows that there is no statistically significant association between the anxiety level of the students who eat breakfast and who do not eat breakfast. As a result, significant value is 0.274 which is greater than the alpha 0.05 . The decision of the result is failed to reject the hypothesis $(\mathrm{H} a)$. It is base on what breakfast the students consumed on that day and what nutrients it gives to them because some students take breakfast which is easy to make and takes less time to cook. Students also take snacks like bread and biscuits with coffee or other drinks as a preload in the morning because this kind of food is easy to ready, even it doesn't give enough nutrients and just energizes them in going to school. Coffee that consists of caffeine may possibly improve the students' memory, logical reasoning, free recall, and recognition memory and could somehow improve their performance in sustained attention tasks, increase blood pressure, and increased mental alertness [21]. But, it doesn't show any support to the hypothesis that breakfast could have an association with the anxiety level of students.

The mental health of individuals only improves if their breakfast consists of more nutrients like cereals and was consumed regularly [8]. So, there might be instances why the result doesn't give any association because we cannot truly know the eating behavior of students towards breakfast and maybe because the breakfast they consume is not healthy. However, other people make eating a larger amount of food as a way of reducing anxiety which is somehow effective [9]. All in all, the result tells that breakfast doesn't have any association with anxiety but maybe on some aspects of mental health and single take of breakfast doesn't leave to a direct effect on the anxiety of a person.

\section{Findings}

In this study, the researcher found that the students, either taking their breakfast or not is having a midlevel of anxiety. Also, both students disagreed with being anxious in school. They feel more likely of being calm and relaxed and don't give too much worry about things. Somehow, the anxiety level of students who eat breakfast and who do not eat breakfast contains a small gap but still doesn't give any impact of the result as it stays in the same mid anxiety level. So, either way, the students eat breakfast or not, the result still is the same and doesn't give any changes at all. Also, the study found that there is no significant association between the anxiety levels of students.

\section{Conclusion}

Breakfast is known to be the most significant meal in a day. It gives numerous benefits to the students who consumed it regularly. However, some students tend to skip breakfast for some reason that may give a negative effect on them, especially to their mental health. Anxiety which is part of mental illness is also occurring to the students particularly in school and was given students some difficulties to learn. However, the study reveals having no association between breakfast and anxiety level of the students. It's accepted that breakfast couldn't give students anxiety levels any impact. But, there still be some other instances that breakfast gives responses to students' mental health.

\section{Recommendations}

Based on the finding and the discussion of this study, the researcher made the following recommendations: 
First, students still need to understand and know more about the importance of breakfast. Also, the students need to regularly eat breakfast that consists of a lot of nutrients for us to have healthier mental, physical, and emotional health.

Second, the parents also need to still give an eye to their children's eating behavior for good performance in school.

Third, for the school to emphasize nutrition and breakfast consumption of students and also implement the feeding program for the enhancement of the students' performance.

Fourth, the study recommends to future researchers to study more about the relations of breakfast and mental illnesses.

\section{Limitations}

There are some limitations in this study that includes fewer respondents that affect that doesn't truly show the relation between breakfast and anxiety. Also, the study focuses on a shorter range of environment that needs for improvements and further inquiry. Thus, for future researchers, much better to include bigger sample size and study must be more reliable.

\section{References}

[1]. Chitra\&Radha Reddy. (2005, November 2). The role of breakfast in nutrient intake of urban school children. Public Health Nutrition, 10(1). doi: 10.1017/S1368980007219640

[2]. University of Waterloo. (2018, March 14). Large numbers of students skipping breakfast. ScienceDaily. Retrieved June 16, 2019 from www.sciencedaily.com/releases/2018/03/180314092256.htm

[3]. Lawton CL, Adolphus K and Dye L (2013). The effects of breakfast on behavior and academic performance in children and adolescents. Front. Hum. Neurosci, 7(425). doi: 10.3389/fnhum.2013.00425

[4]. Hashmat S., Hashmat M., Amanullah F. and Aziz S. (2008). Factors causing exam anxiety in medical students. US National Library of Medicine National Institutes of Health, 58(4), 167-170. https://www.jpma.org.pk/PdfDownload/1364?fbclid=IwAR2TJuPT2dMLGI1kruYiiSI5djgkx3PDB8naxp7t8 gU4NR_Rq3CgqDadgDk

[5]. Gürses A., Kaya Ö., Dogar, C., Günes K., and Yolcu H. (2010). Measurement of secondary school students' test-anxiety levels and investigation of causes.Science Direct, Procedia Social and Behavioral Sciences, 9, 1005-1008. https://doi.org/10.1016/j.sbspro.2010.12.276

[6]. Research History. (2012). A theory of human motivation. Psychological Review, 50, 370-396. http://www.researchhistory.org/2012/06/16/maslows-hierarchy-of-needs/

[7]. McLeod, S. A. (2018, May 21). Maslow's hierarchy of needs. Retrieved from https://www.simplypsychology.org/maslow.html

[8]. Smith, A. P. (1998). Breakfast and mental health. International Journal of Food Sciences and Nutrition, 49(5), 397-402. doi:https://doi.org/10.3109/09637489809089415

[9]. Herman, C. P., \&Polivy, J. (1975). Anxiety, restraint, and eating behavior. Journal of Abnormal Psychology, 84(6), 666-672. doi:http://dx.doi.org/10.1037/0021-843X.84.6.666

[10].Matthys, C., De Henauw, S., Bellemans, M., De Maeyer, M., \& De Backer, G. (2007). Breakfast habits affect overall nutrient profiles in adolescents. Public Health Nutrition, 10(4), 413-421. doi: $10.1017 / \mathrm{S} 1368980007248049$

[11].Deshmukh-Taskar, P. R., Nicklas, T. A., O'Neil, C. E., Keast, D. R., Radcliffe, J. D., \& Cho, S. (2010). The relationship of breakfast skipping and type of breakfast consumption with nutrient intake and weight status in children and adolescents: The national health and nutrition examination survey 1999-2006. Journal of the American Dietetic Association, 110(6), 869-878. doi:https://doi.org/10.1016/j.jada.2010.03.023

[12].Keski-Rahkonen, A., Kaprio, J., Rissanen, A., Virkkunen, M., \&Rose, R. J. (2003). Breakfast skipping and health-compromising behaviors in adolescents and adults. European Journal of Clinical Nutrition, 57, 842853. url:https://www.nature.com/articles/1601618

[13].Smith, K. J., Gall, S. L., McNaughton, S. A., Blizzard. L., Dwyer, T. \& Venn, A. J. (2010). Skipping breakfast: longitudinal associations with cardiometabolic risk factors in the childhood determinants of adult health study. The American Journal of Clinical Nutrition, 92(6), 1316-1325. doi:https://doi.org/10.3945/ajen.2010.30101

[14].Powell, C. A., Walker. S. P., Chang, S. M., \& Grantham-McGregor, S.M. (1998). Nutrition and education: a randomized trial of the effects of breakfast in rural primary school children. The American Journal of Clinical Nutrition, 68(4), 873-879. doi:https://doi.org/10.1093/ajcn/68.4.873

[15].Kleinman, R. E., Hall, S., Green, H., Korzec-Ramirez, D., Patton, K., Pagano, M. E., \& Murphy J. M. (2002). Diet, breakfast, and academic performance in children. Annals of Nutrition \& Metabolism, 46(1), 24-30. doi:https://doi.org/10.1159/000066399 
[16].Chandler, A. K., Walker, S. P., in Connolly, K. and Grantham-McGregor, S. M. (1994). School Breakfast Improves Verbal Fluency in Undernourished Jamaican Children.The Journal of Nutrition, 125(4), 894-900. doi:https://doi.org/10.1093/jn/125.4.894

[17].Rampersaud, G. C., Pereira, M. A., Girard, B. L., Adams, J., \&Metzl, J. D. (2005). Breakfast habits, nutritional status, body weight, and academic performance in Children and adolescents. Journal of the American Dietetic Association, 105(5), 743-760. doi:https://doi.org/10.1016/j.jada.2005.02.007

[18].Astbury, N. M., Taylor, M. A., \& Macdonald, I. A. (2011) Breakfast consumption affects appetite, energy intake, and the metabolic and endocrine responses to foods consumed later in the day in male habitual breakfast eaters. The Journal of Nutrition,141(7), 1381-1389. doi:https://doi.org/10.3945/jn.110.128645

[19].Pollitt, E., \& Mathews, R. (1998). Breakfast and cognition: an integrative summary. The American Journal of Clinical Nutrition, 67(4), 804S-813S. doi:https://doi.org/10.1093/ajen/67.4.804S

[20].Hoyland, A., Dye, L., \& Lawton, C. (2009). A systematic review of the effect of breakfast on the cognitive performance of children and adolescents. Nutrition Research Reviews, 22(2), 220-243. doi: $10.1017 / \mathrm{S} 0954422409990175$

[21].Salmon, J., Smith, A., Kendrick, A., \& Maben, A. (1994). Effects of breakfast and caffeine on cognitive performance, mood and cardiovascular functioning. Appetite, 22(1), 39-55. doi:https://doi.org/10.1006/appe.1994.1004

[22].Cooper, S. B., Bandelow, S., \&Nevill, M. E. (2011). Breakfast consumption and cognitive function in adolescent schoolchildren. Physiology \& Behavior, 103(5), 431-439. doi:https://doi.org/10.1016/j.physbeh.2011.03.018

[23].Mahoney, C. R., Taylora, H. A., Kanareka, R. B., \& Samuel, P. (2005). Effect of breakfast composition on cognitive processes in elementary school children. Physiology \& Behavior, 85(5), 635-645. doi:https://doi.org/10.1016/j.physbeh.2005.06.023

[24].Herman, C. P., \&Polivy, J. (1975). Anxiety, restraint, and eating behavior. Journal of Abnormal Psychology, 84(6), 666-672. doi:http://dx.doi.org/10.1037/0021-843X.84.6.666

[25].Pine, D.S., Cohen, P., Gurley, D., Brook, J., \& Ma, Y. (1998). The risk for early-adulthood anxiety and depressive disorders in adolescents with anxiety and depressive disorders. Arch Gen Psychiatry, 55(1), 5664. doi:10.1001/archpsyc.55.1.56

[26].Eysenck, M. W., Derakshan, N., Santos, R., \&Calvo, M. G. (2007). Anxiety and cognitive performance: Attentional control theory. Emotion, 7(2), 336-353. doi:http://dx.doi.org/10.1037/1528-3542.7.2.336

[27].Schlenker, B. R., \& Leary, M. R. (1982). Social anxiety and self-presentation: A conceptualization model. Psychological Bulletin, 92(3), 641-669. doi:http://dx.doi.org/10.1037/0033-2909.92.3.641

[28].Bagana, E., Raciu, A., \&Lupu, L. (2011). Self-esteem, optimism and exams' anxiety among high school Students. Procedia - Social and Behavioral Sciences, 30,1331 - 1338. doi:https://doi.org/10.1016/j.sbspro.2011.10.258

[29].Wine, J. (1971). Test anxiety and direction of attention. Psychological Bulletin, 76(2), 92-104. doi:http://dx.doi.org/10.1037/h0031332

[30].Hembree, R. (1990). The nature, effects, and relief of mathematics anxiety. Journal for Research in Mathematics Education, 21(1), 33-46. doi: 10.2307/749455

[31].Horwitz, E. K., Horwitz, M. B., \& Cope, J. (1986). Foreign language classroom anxiety. The Modern Language Journal, 70(2), 125-132. doi:https://doi.org/10.1111/j.1540-4781.1986.tb05256.x

[32].Horwitz, E. (2001). Language anxiety and achievement. Annual Review of Applied Linguistics, 21, 112-126. doi: $10.1017 / \mathrm{S} 0267190501000071$

[33].Young, D. J. (1991). Creating a low-anxiety classroom environment: what does language anxiety research suggest? The Modern Language Journal, 75(4), 426-437. doi:https://doi.org/10.1111/j.15404781.1991.tb05378.x

[34].Ashcraft, M. H., \& Kirk, E. P. (2001). The relationships among working memory, math anxiety, and performance. Journal of Experimental Psychology: General, 130(2), 224-237. doi:http://dx.doi.org/10.1037/0096-3445.130.2.224

[35].Ashcraft, M. H. (2002). Math anxiety: Personal, educational, and cognitive consequences. Current Directions in Psychological Science, 11(5), 181-185. doi:https://doi.org/10.1111/1467-8721.00196

[36].Hembree, R. (1990). The nature, effects, and relief of mathematics anxiety. Journal for Research in Mathematics Education, 21(1), 33-46. doi: 10.2307/749455

[37].Cobham, V. E., Dadds, M. R., \& Spence, S. H. (1998). The role of parental anxiety in the treatment of childhood anxiety. Journal of Consulting and Clinical Psychology, 66(6), 893-905. doi:http://dx.doi.org/10.1037/0022-006X.66.6.893 